\title{
Comercio exterior como campo de la cooperación internacional al desarrollo en Paraguay. Los proyectos implementados en el período 2003-2013
}

\author{
Foreign trade as a field of international \\ development cooperation in Paraguay. \\ The projects implemented in the period \\ 2003-2013
}

\author{
María Antonella Cabral López*
}

\begin{abstract}
RESUMEN
El comercio exterior es una de las principales actividades realizadas por las economías y ha sido considerado uno de los campos de la cooperación internacional al desarrollo en las últimas décadas. Este material tiene como objetivo analizar los proyectos implementados en Paraguay en el período 2003-2013. Para ello se recurre a una investigación bibliográfico-documental y de campo, que amalgama revisión de distintas fuentes con entrevistas a informantes calificados. Entre los hallazgos más importantes, pudo constatarse la existencia de temáticas recurrentes como, por ejemplo, la institucionalidad; una mejora en la diversificación de productos como así también en los mercados de destino de las exportaciones paraguayas, aunque la competitividad del país
\end{abstract}

Economista egresada con medalla de oro (FCE-Una). Posee una Maestría en Relaciones Internacionales de la Universidad Nacional de La Plata, Argentina. Tiene una especialización en Procedimientos y Técnicas para la elaboración de tesis y otra en didáctica universitaria. Desde 2011 tiene a su cargo la cátedra de Economía Internacional en la carrera de Economía (FCE-UNA) y actualmente se desempeña como Docente Investigadora de dedicación exclusiva en la Facultad de Ciencias Económicas, Universidad Nacional de Asunción, Paraguay. antocabral@gmail.com. Recibido el 22 de enero de 2018. Modificado el 20 de febrero de 2020. Aceptado el 2 de marzo de 2020. 
sigue siendo baja.

Palabras clave: Comercio exterior - Cooperación internacional - Paraguay - Países en vías de desarrollo - Proyectos JEL: F19; F35.

\begin{abstract}
Foreign trade is one of the main activities of the economies. This issue also has been considered one of the fields of international development cooperation in recent decades. This material aims to analyze the projects implemented in Paraguay in the period 2003-2013. For this is used a bibliographic-documentary and field research, which amalgams the review of different sources with interviews with qualified informants. Some of the most important findings are: the existence of recurring issues, like institutionality and an improvement in product diversification and in the destination markets of Paraguayan exports, although the country's competitiveness remains low.
\end{abstract}

Keywords: Foreing trade - International cooperation - ParaguayDeveloping countries - JEL: F19; F35 projects.

\title{
INTRODUCCIÓN
}

La República del Paraguay, al igual que los demás países del mundo, transitó por distintas etapas en lo que a cooperación internacional se refiere. Entre la década de 1950 y 1980 fue un privilegiado receptor, especialmente de la cooperación estadounidense y de los fondos de origen brasilero en el marco de las decisiones de política exterior del dictador Alfredo Stroessner (Cabral López, 2014).

Sin embargo, con su caída en 1989, inicia un nuevo período con una distinta configuración. Si bien se registraron cambios en materia política, la transición no fue un proceso fácil. $\mathrm{Al}$ respecto, Abente Brun (2019: 27) sostuvo que el período 1989-1993 puede ser considerado como "una etapa de transición de facto" y por diversas circunstancias señala al año 1998 como el inicio de la democracia. Asimismo, en lo que concierne a la economía del país, la década de 1990 tampoco fue muy alentadora. A pesar de la suscripción del Tratado de Asunción, el cual dio nacimiento al Mercosur, el modelo económico imperante, la crisis del sistema financiero y otros aspectos institucionales no permitieron que la economía paraguaya despegue (Masi, 2006; Espínola González, 2010). 
Recién hacia el año 2003 se experimentó una mejora en los indicadores macroeconómicos, la que se prolongó en el tiempo (oCDE, 2018). Pese a la estabilidad de la economía, la misma sigue dependiendo en demasía del sector primario, lo que la expone a factores exógenos como ser la incidencia de fenómenos climáticos o variaciones en los mercados de commodities, entre otros.

En lo referente a su integración económica, existen diversos factores que repercuten en ella. Masi (2006) explica que desde el régimen stronista, el país optó por un modelo de integración basado en la intermediación comercial en el que Paraguay practicaba una apertura comercial que permitía el ingreso de productos importados, especialmente bienes de lujo, para su posterior reexportación a países vecinos. Esto, junto con la falta de políticas específicas para alentar la inversión en el sector productivo y la alta dependencia del sector agropecuario, condujeron a que la oferta exportable sea limitada a pocos productos, situación que persistió durante los primeros años del tercer milenio.

Además del modelo de integración "fronteras adentro", referido previamente (Masi, 2006: 6), la competitividad del país se vio afectada por diversos factores y por la mediterraneidad, la que le supone un costo extra al país de acuerdo con estimaciones del BID (2009:18). Cabe señalar que Paraguay participa de diferentes iniciativas de integración, entre las que destacan: la
Asociación Latinoamericana de Integración (ALAdi) ${ }^{1}$ y el Mercado Común del Sur (Mercosur), y en organismos multilaterales como la Organización Mundial de Comercio (omc) (Tamames \& Huerta, 2010; Cabral López, 2017). A pesar de los esfuerzos efectuados, la inserción internacional del país siguió evidenciando ciertas dificultades en las últimas décadas.

Para hacer frente a las mismas se recurrió a la cooperación de distintos donantes en las últimas décadas. Este material tiene como objetivo analizar los proyectos efectuados por la Cooperación Internacional al Desarrollo (CID) en el campo del comercio exterior (CE) en Paraguay entre 2003-2013. Se optó por este marco de tiempo debido a que coincidía con los últimos dos períodos gubernamentales completos al momento de la redacción del material.

Para ello, se estructuró este artículo en cuatro partes. En la primera se plantea el tema de Bienes Públicos Globales como justificación teórica para el abordaje de proyectos relacionados a CE en la cid. En la segunda se profundiza esta idea, presentando la incidencia del CE en el desarrollo, para pasar, en la tercera parte, a la presentación de los proyectos implementados en la materia en el Paraguay (2003-2013). En el último apartado se realiza un

1 Fue creada mediante el Tratado de Montevideo en 1980 y sirvió como sustituta de la Asociación Latinoamericana de Libre Comercio fundada en 1960. 
análisis general de estos y se presentan aspectos cuantitativos y cualitativos relevantes del CE paraguayo como parámetro de sus resultados.

\section{Bienes públicos globales y la cooperación internacional}

A modo de introducción al estudio del CE como uno de los campos en los que actúa la CID, se considera, en primera instancia, la teoría de los bienes públicos como un instrumento teórico que permite ahondar en la temática. Desde que Samuelson (1954) publicase The Pure Theory of Public Expediture se han desarrollado variadas investigaciones al respecto, entre las que pueden reseñarse los aportes de Musgrave (1959) y Buchanan (1965), que complementaron al modelo inicial (Ramis Olivos, 2013). A partir de estos trabajos se evidenciaron dos características en los bienes públicos: la no exclusión, explicada por Stiglitz (2000) como la imposibilidad de impedir a otro sujeto su uso y ejemplificada con el usufructo de un faro, y la no rivalidad en el consumo, la cual considera como la posibilidad de que una persona consuma, sin impedir o reducir que otra lo haga también; lo que puede ser ilustrado con bienes como la defensa nacional.

A partir de estas dos características, Ramis Olivos (2013) -en base a Ostrom (2006)- presenta una tipología de los bienes, la que se refleja en la Tabla 1, en la que pueden apreciarse distintos ejemplos. El enfoque de Samuelson, típico de la economía de bienestar, buscó explicar el papel del Estado en la actividad general. El mismo podía proveer entonces los bienes que no cumplen los requisitos de públicos puros, como ser la educación, la infraestructura, los servicios públicos, entre otros (D'Alisa, 2013). Adicionalmente, Stiglitz (2000) explica que además de bienes públicos, el Estado también podría proveer bienes privados como el agua.

Es importante destacar que los bienes públicos pueden generarse en distintos planos territoriales y conforme a su alcance geográfico —-según García Arias (2004) - pueden ser clasificados en las siguientes categorías: i) Local,ii) Nacional, iii) Regional y iv) Internacional. La primera de estas categorías contempla los bienes que afectan a una porción de un país; la segunda a aquellos que repercuten en todo el territorio nacional; mientras que la tercera se refiere a los que afectan a varios países con cierta proximidad, y la última a los que involucran a una variedad de países. Al respecto, de la última categoría mencionada, la de los bienes públicos internacionales, esta puede ser global si involucra a un número importante de países heterogéneos, a distintos grupos socio-económicos y a diferentes generaciones.

Por lo anteriormente expuesto, la categoría de los bienes públicos globales (BPG) también puede evidenciar distintos niveles de exclusión y rivalidad. Sandler (2002) señala cinco categorías: i) BPG puros; ii) BPG impuros parcialmente rivales; (iii) BPG impuros 
Tabla 1: Tipología de bienes

\begin{tabular}{|l|l|l|}
\cline { 2 - 3 } \multicolumn{1}{c|}{} & RIVALIDAD BAJA & RIVALIDAD ALTA \\
\hline Exclusión difícil & $\begin{array}{l}\text { Bienes públicos puros. } \\
\text { Puestas del sol, } \\
\text { conocimientos } \\
\text { acumulados. }\end{array}$ & $\begin{array}{l}\text { Bienes públicos impuros } \\
\text { o bienes comunes. } \\
\text { Bibliotecas, sistemas de } \\
\text { regadío. }\end{array}$ \\
\hline Exclusión fácil & $\begin{array}{l}\text { Bienes privados impuros, } \\
\text { de club o de peaje. } \\
\text { TV por cable, Guarderías } \\
\text { infantiles. }\end{array}$ & $\begin{array}{l}\text { Bienes privados puros. } \\
\text { Notebooks, ropas. }\end{array}$ \\
\hline
\end{tabular}

Fuente: Ramis Olivos (2013).

parcialmente excluibles; iv) вPG de Club, у v) вPG joint products. Las características de cada una de las primeras cuatro son análogas a las descritas precedentemente en la Tabla 1 , mientras que la última refleja una situación especial en la que en la medida que aumentan los beneficios excluibles, pueden aumentarse los pagos. Este autor considera en esta última categoría a la cooperación internacional.

Para proseguir con la clasificación de los BPG, Kaul et al. (1999) establece otra propuesta basada en el origen. Las categorías establecidas por estos autores son: i) вPG naturales; ii) вPG producidos, y v) BPG derivados de la acción política ${ }^{2}$. La primera de ellas se refiere a bienes que son preexistentes a la acción humana, como ser la

2 Los nombres originales de estas categorías en el idioma original son: Natural global commons; Human-made commons y Policy outcomes. capa de ozono o la atmósfera. Mientras que la segunda refleja aquellos creados por el hombre como el acervo de conocimientos o la normativa universal como los derechos humanos que se reflejan en una variable de stock. Por último, la tercera también fue creada por el hombre pero, a diferencia de la categoría anterior, es un flujo y no un stock (García Arias, 2004), por lo que su mantenimiento requiere de una acción constante; ejemplos de esto son la paz y la equidad global.

Por su parte, Morrissey et al. (2002) aportan dos clasificaciones, una de ellas basada en la utilidad y la otra en el ámbito del que emerge el BPG. Así encontramos las siguientes categorías conforme al primer criterio: i) BPG que proveen de utilidad directamente, como por ejemplo la biodiversidad; ii) BPG que reducen el riesgo, entre los que podría considerarse la reducción de inestabilidad financiera, y iii) BPG que aumentan capacidades, los que 
pueden ser ilustrados con modelos como los de las instituciones de gobernanza global.

En cuanto al ámbito del que emerge el врG, Morrissey et al. (2002) refieren que los mismos pueden ser de los siguientes sectores: i) Medioambiental, ii) Sanitario, iii) Cognitivo, iv) Seguridad, y v) Gobernanza. Para este último sector considera como actividad principal las instituciones multilaterales y el gobierno de los bienes, mientras que como actividad complementaria señala el fortalecimiento de la sociedad civil y las reformas en el servicio civil.

En base a lo expuesto, a través de las distintas clasificaciones se percibe la existencia de elementos que vinculan a la cooperación internacional y sus temáticas, con la perspectiva de los BPG. En este sentido, Kaul \& Blondin (2015) abordan la misma perspectiva, que vincula a los BPG con los desafíos internacionales contemporáneos y consideran, tal como predice la teoría económica, la emergencia de problemas de acción colectiva y subabastecimiento ${ }^{3}$.

Estos autores señalan que debido a que existe una desconcentración vertical y horizontal de la gobernanza, se dan respuestas ad-hoc y experimentales a los problemas, lo que hace que el mundo viva su propio "Dilema del

3 Para abordar más en profundidad estos temas se recomienda la lectura de Stiglitz (2000).
Prisionero" ${ }^{4}$. Para hacer frente a esto proponen dos estrategias: a) conceptualización y prueba de un fundamento para una cooperación internacional eficaz y justa que la vuelva compatible con la soberanía, y b) en base a lo recabado, la construcción de un consenso mundial respecto de la noción de "soberanía inteligente” (Kaul \& Blondin, 2015; pág. 73).

Este tipo de soberanía reconoce la imposibilidad que tiene un país, más allá del poder que posea, de solucionar por sí solo un problema ante la existencia de interdependencia. Por ello, sostienen los autores anteriormente citados, que el mismo recurre a la cooperación internacional para este tipo de asuntos y trata mediante ella de eliminar las externalidades negativas que delimitan su capacidad de formular políticas. En el mismo sentido, Calabuig Tormo et al. (2010: 36) también destacan que debido al proceso de globalización los BPG han dejado de tener un cariz doméstico y se han convertido en un patrimonio internacional, lo que necesariamente implica

4 El mismo señala que una estrategia individualmente racional conduce a resultados colectivamente no racionales. Es junto con "La tragedia de los bienes comunes" de Hardin (1968) y "La lógica de la acción colectiva" de Olson (1968) de los modelos más influyentes sobre bienes públicos, aunque existen grandes críticas a los mismos, entre las que de destacan los desarrollos de Elionor Ostrom, galardonada en 2009 con el Premio Nobel por sus contribuciones en materia de economía institucional de los bienes comunes. 
cierto esfuerzo conjunto entre Estados u organismos internacionales.

Por último, cabe señalar que en los últimos años ha existido una mayor consideración sobre el tema de los bienes públicos y los bienes comunes (D’Alisa, 2013), así como también en lo que respecta a la economía pública internacional. García Arias (2004: 191) sostiene que "la mayor integración de los mercados y una creciente interdependencia entre las diferentes economías nacionales, ha generado (o simplemente acentuado, en algunos casos concretos) una visión más global respecto de las consideraciones de provisión eficiente y de financiación de los bienes públicos".

Luego de haber presentado algunos de los aspectos que vinculan la noción de BPG con la CID, en el siguiente apartado se profundiza en lo que respecta al comercio exterior como una de las temáticas de la misma.

\section{EL COMERCIO EXTERIOR EN LA COOPERACIÓN INTERNACIONAL}

Luego de haber considerado, desde la teoría de BPG, la validez de la CID para abordar aquellos problemas que afectan a diversos países, en estas líneas se expondrá al CE como una de esas temáticas. Según la Conferencia de las Naciones Unidas sobre Comercio y Desarrollo (UnCTAD, 2018), el comercio puede brindar su aporte positivo al desarrollo sostenible. Sin embargo, para que esto se concrete, el proceso no es automático, sino que es preciso que las políticas sean diseñadas de manera que esto suceda.

Las condiciones o reglas que rigen el comercio han hecho que aspectos como: el precio internacional de los bienes, las barreras paraarancelarias, los subsidios a los productores, entre otros, hayan motivado distintas discusiones en torno a ellos. Prado Lallande (2003: 8) explica que los países en desarrollo han solicitado una serie de medidas que favorezcan su posición poco aventajada. Entre las mismas se encontraban: la liberalización de la agricultura, la reducción de los aranceles, cooperación técnica para la mejora de la competitividad y que ciertas medidas preferenciales estén incluidas en la "caja del desarrollo", entre otros. Estos requerimientos se hicieron patentes en diversas reuniones multilaterales, como ser la Ronda de Doha y Conferencia Internacional de Financiamiento para el Desarrollo, pero los resultados no han sido muy auspiciosos para los países en desarrollo.

Escribano Francés (2012: 42) afirma, por su parte, que son varios los teóricos que han propuesto, desde todos los paradigmas, su conformidad con que los países desarrollados muestren una actitud más favorable hacia los menos favorecidos, lo que se traduciría en mayores facilidades para las exportaciones provenientes de estos y un mayor flujo de cooperación 
técnica financiera. De acuerdo con este autor, esto facilitaría el desarrollo de estos países.

Tabares, Anzo, \& Estrada (2014: 316) afirman que los programas desarrollados por la CID en el campo del CE son pertinentes por su complementariedad con las acciones del sector público y por permitir que exista cierta relación entre los mercados emergentes, como lo son los latinoamericanos con aquellos más desarrollados. Por ello, en esta relación de cooperación internacional las partes ajustan su comportamiento para generar un beneficio mutuo según estas autoras. Ellas remarcan que este tipo de proyectos son especialmente importantes para las Pequeñas y Medianas Empresas (Pymes), las cuales tienen presupuestos mínimos y múltiples necesidades. Pese a la relevancia ya expuesta, el CE como tema de la CID es una cuestión bastante reciente según Álvarez Orellana (2012). Sin embargo, un documento de gran relevancia para el sistema de cooperación internacional, como lo es la Agenda 2030, manifiesta su importancia. Conforme a UNCTAD (2018), el comercio puede ser un medio de implementación de este ambicioso programa de trabajo, lo que queda en evidencia con la Tabla 2. En ella se observa su interacción en las dimensiones: económica, social y ambiental del desarrollo sostenible. 
Comercio exterior como campo de la cooperación internacional al desarrollo en Paraguay. Los proyectos implementados en el período 2003-2013

Tabla 2: El comercio como medio de implementación de la Agenda 2030

\begin{tabular}{|l|l|}
\hline Dimensión & Meta \\
\hline Económica & $\begin{array}{l}\text { Referencias directas al comercio } \\
\text { Meta 8.a Aumentar el apoyo a la iniciativa de ayuda } \\
\text { para el comercio en los países en desarrollo (PeD), en } \\
\text { particular los países menos adelantados (PMA). } \\
\text { Meta 10.a Aplicar el principio del trato especial y dife- } \\
\text { renciado para los PeD, en particular los PMA, de confor- } \\
\text { midad con los acuerdos de la omc. } \\
\text { Meta 17.10 Promover un sistema de comercio multila- } \\
\text { teral universal, basado en normas, abierto, no discrimi- } \\
\text { natorio y equitativo en el marco de la omc, incluso me- } \\
\text { diante la conclusión de las negociaciones en el marco } \\
\text { del Programa de Doha. } \\
\text { Meta 17.11 Aumentar significativamente las exportacio- } \\
\text { nes de los PeD, en particular con miras a duplicar la } \\
\text { participación de los pma en las exportaciones mundia- } \\
\text { les de aquí a 2020. } \\
\text { Meta 17.12 Lograr la consecución oportuna del acceso } \\
\text { a los mercados libre de derechos y contingentes de ma- } \\
\text { nera duradera para todos los pma. } \\
\text { Ejemplos de otros vinculos con el comercio } \\
\text { Objetivo 1 El comercio brinda oportunidades de ge- } \\
\text { neración de ingresos y puede reducir los precios de los } \\
\text { alimentos y bienes de consumo, contribuyendo así a } \\
\text { reducir la pobreza } \\
\text { Objetivo 8 El comercio puede contribuir a crear em- } \\
\text { pleo y mejorar las remuneraciones y las condiciones } \\
\text { de trabajo. }\end{array}$ \\
\hline
\end{tabular}




\begin{tabular}{|l|l|}
\hline Social & $\begin{array}{l}\text { Referencias directas al comercio } \\
\text { Meta 2.b Corregir y prevenir las restricciones y dis- } \\
\text { torsiones comerciales en los mercados agropecuarios } \\
\text { mundiales, entre otras cosas mediante la eliminación } \\
\text { paralela de todas las formas de subvenciones a las ex- } \\
\text { portaciones agrícolas de conformidad con el mandato } \\
\text { de la Ronda de Doha. } \\
\text { Meta 3.b Apoyar las actividades de investigación y de- } \\
\text { sarrollo de vacunas y medicamentos para las enferme- } \\
\text { dades transmisibles y no transmisibles que afectan pri- } \\
\text { mordialmente a los países en desarrollo y facilitar el } \\
\text { acceso a medicamentos y vacunas esenciales asequibles } \\
\text { de conformidad con la Declaración de Doha relativa al } \\
\text { Acuerdo sobre la Salud Pública y, en particular, propor- } \\
\text { cionar acceso a los medicamentos para todos. } \\
\text { Ejemplos de otros vínculos con el comercio } \\
\text { Objetivo } 5 \text { El comercio puede proporcionar empleo } \\
\text { y brindar oportunidades de generación de ingresos a } \\
\text { las mujeres, contribuyendo así a su empoderamiento. } \\
\text { Objetivo 16 Los compromisos vinculantes contraídos } \\
\text { en virtud de acuerdos comerciales pueden contribuir a } \\
\text { crear instituciones eficaces, responsables y transparentes. }\end{array}$ \\
$\begin{array}{l}\text { Referencias directas al comercio } \\
\text { Meta 14.6 De aquí a 2020, prohibir ciertas formas de } \\
\text { subvenciones a la pesca que contribuyen a la sobreca- } \\
\text { pacidad y la pesca excesiva, reconociendo que la nego- } \\
\text { ciación sobre las subvenciones a la pesca en el marco } \\
\text { de la omc debe incluir un trato especial y diferenciado, } \\
\text { apropiado y efectivo para los PeD y los pMa. } \\
\text { Ejemplo de otros vínculos con el comercio } \\
\text { Objetivo12 Las medidas no arancelarias pueden regular } \\
\text { la producción y prohibir y/o controlar las importacio- } \\
\text { nes de productos que causan daños al medio ambiente } \\
\text { Objetivo13 Las medidas no arancelarias pueden regular } \\
\text { la producción y el comercio con respecto a las emisio- } \\
\text { nes de carbono, de acuerdo con la Convención Marco } \\
\text { de las Naciones Unidas sobre el Cambio Climático y } \\
\text { su Protocolo de Kyoto. }\end{array}$ \\
\hline Ambiental
\end{tabular}


En cuanto a la financiación del desarrollo, Prado Lallande (2003) refiere que existe un consenso reciente sobre la eficacia de los flujos financieros externos para incentivar el crecimiento económico y los clasifica en tres fuentes externas de financiamiento al desarrollo: privadas, públicas y mixtas. Entre las primeras considera a los capitales provenientes del comercio exterior, las inversiones extranjeras y los préstamos de instituciones financieras internacionales. Las públicas, por su parte, se vinculan con los fondos provenientes de otros Estados y organismos multilaterales, donde la ayuda oficial al desarrollo (AOD) tiene un lugar privilegiado, mientras que las mixtas combinan ambos tipos de fuentes. Alonso (2015, pág. 171) también enuncia diversas fuentes de financiamiento, entre las que cita: amplía las anteriores, añadiendo formas innovadoras, entre las que se encuentran, por mencionar solo algunos ejemplos: la Responsabilidad Social Corporativa, las contribuciones privadas al sistema de cooperación al desarrollo y mecanismos de desarrollo limpio, etc.

Cabe también señalar que la financiación existente en las fuentes tradicionales, especialmente en la AOD, se destina a diversos instrumentos. Calabuig Tormo et al. (2010) reflejan ejemplos de estos, los cuales se recogen en la Tabla 3. 
Tabla 3: Instrumento para la cooperación en comercio exterior

\begin{tabular}{|l|l|}
\hline INSTRUMENTO & DESCRIPCión \\
\hline $\begin{array}{l}\text { Preferencias } \\
\text { comerciales }\end{array}$ & $\begin{array}{l}\text { Permiten que los países industrializados eliminen total } \\
\text { o parcialmente las barreras comerciales (aranceles, cuo- } \\
\text { tas, etc) a una parte o a la totalidad de las exportaciones } \\
\text { de los países en desarrollo. }\end{array}$ \\
\hline $\begin{array}{l}\text { Cooperación } \\
\text { económica }\end{array}$ & $\begin{array}{l}\text { Son acciones que se dirigen a fortalecer el sector pro- } \\
\text { ductivo de los países que han alcanzado un cierto nivel } \\
\text { de desarrollo y va dirigido a sectores con potencial. }\end{array}$ \\
\hline fyuda & $\begin{array}{l}\text { Incluye distintas modalidades de transferencia y acceso } \\
\text { al capital. } \\
\text { Algunos ejemplos de ella son: el apoyo al presupues- } \\
\text { to del Estado del país receptor para financiar el gasto } \\
\text { corriente o la inversión pública en actividades que se } \\
\text { consideren prioritarias para el desarrollo; los microcré- } \\
\text { ditos destinados a fomentar el desarrollo productivo } \\
\text { de determinados sectores; las concesiones de líneas de } \\
\text { crédito preferencial para la importación de bienes y ser- } \\
\text { vicios del país donante a través de los mecanismos de } \\
\text { ayuda ligada, y la transferencia de fondos para apoyar la } \\
\text { balanza de pagos y fortalecer las reservas del país bene- } \\
\text { ficiario, entre otros. }\end{array}$ \\
\hline $\begin{array}{l}\text { Asistencia } \\
\text { técnica }\end{array}$ & $\begin{array}{l}\text { Proporciona conocimientos y habilidades técnicas y de } \\
\text { gestión cualificando a los recursos humanos del país } \\
\text { receptor. }\end{array}$ \\
\hline Comercio justo & $\begin{array}{l}\text { Consiste en la reivindicación de unas reglas comercia- } \\
\text { les más justas. Incluyen condiciones como salario dig- } \\
\text { no de los trabajadores, sin discriminación de género y } \\
\text { explotación laboral infantil, etc. }\end{array}$ \\
\hline
\end{tabular}


Lo expuesto hasta aquí permite hacer patente la relevancia del CE para la cID. A continuación, se plantearán los distintos proyectos implementados en Paraguay en el periodo de referencia y se analizarán los mismos.

\section{Proyectos de CID en materia de CE con}

el Paraguay (2003-20I3)

Es menester señalar, antes de iniciar el detalle de los proyectos, algunas consideraciones institucionales relacionadas a la cooperación. El marco legal de la misma está integrado por diversas normativas, empezando por la Constitución Nacional (1992), la que reconoce como principio "la solidaridad y la cooperación internacional”; leyes; decretos y resoluciones emanados del Poder Ejecutivo, de las tres instituciones gubernamentales a cargo de su gestión. Estas son: la Secretaría Técnica de Planificación (STP), el Ministerio de Hacienda ( $\mathrm{MH}$ ) y, naturalmente, el Ministerio de Relaciones Exteriores (MRE) (STP, MRE \& MH, 2012).

El MRE es el que conduce las negociaciones sobre asuntos vinculados a la cooperación internacional en coordinación con otros órganos estatales. El $\mathrm{MH}$, por su parte, se encarga del pago de las deudas contraídas, y la STP tiene entre sus funciones proponer y evaluar la cooperación técnica, conducir - en solitario o con otras carteras-negociaciones para la obtención de financiamiento para la cooperación técnica, y ejecutar los convenios que se suscriban en materia de cooperación (Decreto 4070/2004; Art. 6). De acuerdo a la naturaleza del proyecto a ser ejecutado, el mismo puede contar con la participación de distintos organismos ejecutores.

Cabe destacar que Paraguay ha recibido cooperación bilateral y multilateral en diversos temas y de distintos cooperantes. Algunos de estos son: el Banco Interamericano de Desarrollo (BID), la Japan International Cooperation Agency (JiCa), la Unión Europea (UE), los Estados Unidos y la República de China-Taiwán. En las próximas líneas se detallarán los proyectos impulsados por estos donantes en materia de comercio exterior.

\section{BID}

Es considerada como una de las principales fuentes de financiamiento de los proyectos de desarrollo del país. Este canaliza su labor en materia de comercio a través de tres líneas de trabajo: los préstamos para el sector privado, el sector público y la cooperación técnica. Financió 18 proyectos en este sector, de los cuales 10 fueron en el período 2003-2013. De estos 10, solo tres están vinculados a la capacidad institucional del Estado para promover las exportaciones e inversiones y siete están direccionados al sector privado. 
De los proyectos con el sector público, solo el denominado "Programa de Apoyo a las Exportaciones Paraguayas (PAEP)" es considerado, debido a que uno de ellos era un proyecto pequeño de una financiación de USD 86.565 y el otro fue aprobado en diciembre de 2013, lo que lo excluye del alcance de este trabajo. Esta última razón justifica también la exclusión del análisis de la cooperación brindada por el BID para la aprobación del nuevo Código Aduanero, ya que pese a su impacto en el comercio exterior, la misma está categorizada como apoyo a la institucionalidad.

El PAEP surge a partir de una solicitud del Gobierno de Paraguay de una operación que sirva de apoyo para la internacionalización de las empresas paraguayas. Los resultados esperados fueron: incremento del número de empresas exportadoras; incremento del número de nuevos productos exportados; e incremento del número de empresas que logran mantener sus exportaciones (BID, 2006a:1). El Ministerio de Industria y Comercio (MIC) fue la agencia ejecutora del mismo, el cual tenía un costo total de USD 13 millones, de los que usD 10 millones serían financiados por el BID y USD 3 millones serían la contrapartida local (BID, 2006b:1).

\section{JICA}

En el campo del comercio, los proyectos desarrollados por la JicA han sido muy valiosos. A pesar de estar fuera del período considerado en este material, el "Estudio sobre el desarrollo económico inclusivo del Paraguay” (EDEP) ha sido muy importante y los insumos generados por el mismo sirvieron para distintos proyectos futuros, razón por la que se lo considera en este estudio. El EDEP proponía la creación de clusters y cadenas agroalimentarias, tomando como fundamento la existencia de distintos productos agrícolas con potencial. De un total de 32 rubros considerados para nuevos clusters, se priorizaron 13, entre ellos: soja, melón, trigo, tomate, maíz, paraíso gigante, sorgo, carne vacuna, mandioca, cerdo, algodón, pollo y naranja (CEPAL \& JiCA, 2013: 23).

Además identificó algunas cadenas incipientes con potencial, pero sin el suficiente encadenamiento para obtener ganancias de su economía de escala y propuso el fortalecimiento de las industrias manufactureras a través del régimen de maquila y una mejora en los niveles de calidad y productividad. De manera no prioritaria, se consideró el aumento en inversión pública en infraestructura y se esbozaron propuestas como "Un producto, un pueblo", que promovía la especialización de los pueblos en ciertos productos.

La JiCa también apoyó un proyecto vinculado a la maquila, el cual fue producto de una cooperación trilateral entre Japón, México y Paraguay. El mismo se denominaba "Promoción y Fortalecimiento del Sistema Maquilador en el Paraguay" y fue desarrollado entre los años 2004-2007 (Uscanga, 2011). Estaba dividido en tres 
áreas: estratégica, operativa y jurídica, las que poseían los siguientes objetivos: mejorar el ambiente de negocios del sistema maquilador; establecer un sistema digital integrado para disminuir los tiempos y transparentar la gestión, y volver más simple y moderno el marco jurídico que rige la actividad. El informe preparado por la CEPAL \& JICA (2013, p.191) señala que los resultados más importantes de este proyecto fueron el mejoramiento de los plazos para la aprobación de un programa de maquila dentro del Consejo Nacional de Industrias Maquiladoras de Exportación (CNIME); el aumento de programas aprobados, y el repunte en el valor de las exportaciones. La mencionada publicación también destaca que los logros se profundizaron luego de la finalización del proyecto y que los mismos permiten atraer capital extranjero y generar empleos decentes en el país.

\section{UE}

Ha cooperado, en reiteradas ocasiones, en la inserción internacional de la economía paraguaya. Esto puede apreciarse en que, desde la firma del primer tratado bilateral con el Paraguay en 1992, se han emprendido diversos proyectos en torno al tema, el cual aparece como un eje de su cooperación en los Documentos de Estrategia País elaborados para los períodos 2001-2006 y 2007-2013. Un aspecto considerado clave en esta cooperación fue el interés en la relación entre la UE y el MERCosur.

Para el período 2003-2013, una de las acciones con mayor resonancia fue el Proyecto de Fortalecimiento de la Competitividad del Sector Exportador Paraguayo (FoCoSEP). Esta iniciativa, cuyo propósito era aportar al desarrollo económico del país por medio de su sector productivo y exportador, comenzó en el año 2004 y se extendió hasta 2009. La misma contaba con tres componentes fundamentales: fortalecimiento del sistema nacional de la calidad; fortalecimiento de las instituciones de inspección y vigilancia sanitaria, y fortalecimiento de los cluster del sector privado. La contribución de la Comisión Europea ascendería a $€ 13$ millones y la contrapartida del gobierno paraguayo sería de $€ 2,9$ millones (Delegación de la Comisión Europea en Paraguay, 2009:20).

Otro de los proyectos de gran envergadura implementados por la UE fue el de Apoyo a la Internacionalización Económica del Paraguay (AIEP). El mismo data de 2006 cuando fue identificado, para posteriormente ser diseñado en 2008. La firma del acuerdo entre la Comisión Europea y Paraguay se concretó finalmente en 2009. Para su implementación debió pasar por la aprobación del Congreso (2010) y la promulgación de parte del Poder Ejecutivo que, por medio de la Ley № 4085, oficializó su realización (AIEP, 2013).

A través de este se pretendía fortalecer la capacidad de las instituciones nacionales para hacer frente a la globalización, además de aumentar y diversificar el comercio exterior de productos no tradicionales, valiéndose de 
procedimientos aduaneros simplificados (tanto antes de la operación como después), asistencia para enfrentar las barreras técnicas y la mejora de la capacidad para satisfacer a la demanda por parte de la empresa. Para su implementación, la contraparte designada fue el mic (Delegación de la Comisión Europea en Paraguay, 2009).

Esto se tradujo en cinco actividades estratégicas y seis sectores priorizados: metalmecánico; manufacturas de cuero, frutas y hortalizas procesadas; textil y confecciones; hierbas medicinales (inclusive Stevia) y aromáticas, y TIC. El costo total del proyecto sería de unos $€$ 7.260.000, de los cuales la Comisión Europea aportaría $€$ 6.000.000, mientras que el gobierno paraguayo asumiría la diferencia (AIEP, 2013).

Otra de las iniciativas en la materia de la que se benefició el país es el Sistema de Preferencias Generalizadas Plus (SPG+).El principal objetivo de este régimen es contribuir a fomentar el desarrollo sostenible y la gobernanza. El mismo otorga incentivos para que los países en desarrollo puedan aplicar un conjunto de convenios que permitan el cumplimiento de ciertos estándares internacionales en ámbitos como los derechos humanos, las normas fundamentales de trabajo, desarrollo sostenible y gobernanza (Comisión Europea, 2008).

\section{EE.UU.}

La cooperación estadounidense con Paraguay en materia comercial consta de varias aristas. A través de la Agencia de los Estados Unidos para el Desarrollo Internacional (USAID, por su sigla en inglés) impulsó distintos programas que de manera directa o indirecta buscaban promover el comercio exterior del país. Particularmente se abordarán el Programa Paraguay Productivo (PPP), la cooperación trilateral, Paraguay Vende y el Programa Umbral.

El ppp tenía como propósito estimular la participación de pequeños productores en cadenas de valor de alto crecimiento y de gran potencial, de manera de vincularlos con compradores e inversores, al tiempo que se les proveía de asistencia técnica y financiera para cumplir con este propósito. Estas acciones se emprendieron en un marco de cooperación con distintos actores, entre los que se encuentra el gobierno paraguayo, el sector privado e instituciones de microfinanzas, entre otros (CARANA Corporation, s.f.:3).

La estrategia del proyecto se llamó "Creando Alianzas para Vender" y pretendió robustecer el vínculo entre todos los agentes de la cadena, incluyendo a agricultores, agroindustrias, cooperativas y el sector financiero. Recién a partir de esta asociación, el programa preveía que se realice la asistencia técnica y financiera requerida. Este relacionamiento permitió también que se identifiquen aquellos problemas que se manifiestan a lo largo de toda la cadena, desde el cultivo hasta la financiación (CARANA Corporation, n.d.).

La USAID impulsó también actividades de cooperación trilateral junto 
con Chile, entre las cuales se encontraban tres programas vinculados al comercio exterior: asistencia técnica y capacitación a la Dirección Nacional de Aduanas (DNA); asistencia técnica y capacitación al Ministerio de Agricultura y Ganadería, y el fortalecimiento del sistema de información comercial de la Red de Inversiones y Exportaciones (REDIEX), por medio de un catastro exportador y el desarrollo de capacidades de inteligencia de mercado (STP, MRE \& MH, 2012).

Otro de los proyectos fue "Paraguay Vende", el cual tuvo dos fases (20032007) y (2007-2010). El monto total del programa fue de usD 9 millones y se basó en el enfoque de cadena de valor que unía a los productores agropecuarios, los compradores de sus productos, las empresas que los convierten en productos finales y los consumidores; lo que estaba acompañado por asistencia técnica focalizada a los 13 sectores asistidos (Chemonics International Inc., 2010: 5). Además se llevaron a cabo dos proyectos relacionados con esta iniciativa: estudios sectoriales de calidad que permitan desarrollar y/o potenciar nuevos sectores y el proyecto "Tu producto al Súper”, el cual pretendía acercar los productos de PYMEs a los supermercados.

Por su parte, el Programa Umbral tuvo dos fases (2006-2008 y 2009-2011) y contaba con 10 ejes de trabajo para luchar contra la corrupción y la informalidad económica ("Programa uMBRAL," n.d.). Entre los temas abordados, en materia de CE, cabe destacar la creación de la Ventanilla Única del Importador, la que se constituyó en una herramienta del conocido como "gobierno electrónico", con la que podrían reducirse los costos, aumentar los controles y con ello las transferencias que se realizan previa y posteriormente al despacho (DNA, 2010). Finalmente, cabe destacar que en 1976 EE.UU. otorgó a Paraguay un SPG (oMc, s.f.).

\section{República de China-Taiwán}

Paraguay es uno de los aliados internacionales más importantes de la República de China-Taiwán. En el marco de este relacionamiento, la cooperación ha sido intensa desde la década de 1960. En el período abordado en este trabajo caben destacar dos iniciativas: el otorgamiento de fondos para la creación de la REDIEx y el apoyo para las empresas paraguayas que quieran incursionar en el mercado taiwanés.

En lo que respecta al primer proyecto, la REDIEx fue creada en 2004 como un piloto para incentivar el crecimiento de la competitividad del país. Si bien desde el principio contó con el apoyo del sector privado, fue articulada desde el mic para promover la inversión extranjera y las exportaciones paraguayas.

La segunda iniciativa en materia de CE se basó en el apoyo a empresas paraguayas que quieran incursionar en el mercado taiwanés. Para conocer más sobre el tema, se recurrió a una entrevista con el Sr. Chi Tang Tsai (2016), Encargado del Área Comercial de la Embajada de China (Taiwán), 
ante la escasez de fuentes disponibles en el tema. Durante el encuentro, el diplomático explicó que se articulan distintas medidas de apoyo para las empresas paraguayas, las que incluyeron la información a empresas con oferta exportable, la colaboración en las misiones comerciales a dicho país y el otorgamiento de facilidades para la participación en importantes ferias monográficas en Taipei.Esta última acción incluye el espacio de exposición y otros servicios como ser el de traducción y armado de agenda de reuniones. Estos aportes no se encuentran sistematizados en documentos específicos de acceso público.

Además de los proyectos emprendidos por los donantes previamente mencionados, también Paraguay fue beneficiario de distintos SPG. En la Tabla 4 puede apreciarse el listado total, conforme a омc (s.f.).

Tabla 4: SPG otorgados a Paraguay vigentes a 2013

\begin{tabular}{|l|l|l|}
\hline $\mathbf{N}^{\circ}$ & Otorgante & Entrada en vigor \\
\hline 1 & Armenia & $06 / 04 / 2016$ \\
\hline 2 & Australia & $01 / 01 / 1974$ \\
\hline 3 & Canadá & $01 / 07 / 1974$ \\
\hline 4 & Estados Unidos de América $^{5}$ & $01 / 01 / 1976$ \\
\hline 5 & Federación de Rusia $^{5}$ & $01 / 01 / 2010$ \\
\hline 6 & Japón $^{\prime}$ & $01 / 08 / 1971$ \\
\hline 7 & Kazajstán & $01 / 01 / 2010$ \\
\hline 8 & Noruega & $01 / 10 / 1971$ \\
\hline 9 & Nueva Zelandia & $01 / 01 / 1972$ \\
\hline 10 & Suiza & $01 / 03 / 1972$ \\
\hline 11 & Turquía & $01 / 01 / 2002$ \\
\hline 12 & Unión Europea & \\
\hline
\end{tabular}

Fuente: OMC (s.f)

5 Este beneficio culminó el 10/10/2016 y entró en vigencia otro nuevo.

6 Este beneficio culminó el 31/12/2018. 


\section{ANÁLISIS DE LOS PROYECTOS EMPRENDIDOS}

En este apartado se busca analizar de manera cuantitativa y cualitativa cómo se desarrollaron los proyectos señalados anteriormente. Para ello, se partirá de una matriz de fortalezas, oportunidades, debilidades y amenazas (FODA), referente al contexto en el que se llevan adelante los proyectos de CE como campo de la cid en el país, la que puede apreciarse en la Tabla 5 . Este instrumento permite tener un panorama general y fue elaborado en base a informes de los donantes y a la realización de entrevistas. En lo que concierne a estas últimas, se contactó a informantes calificados como: autoridades del gobierno paraguayo y funcionarios de las instituciones donantes, de manera de conocer su perspectiva en torno al tema ante la vacancia de información. Cabe destacar que según la омc (2020) los tres temas principales de la cooperación en la materia fueron: diversificación de exportaciones, desarrollo de servicios e infraestructura transfronteriza.

Tabla 5: FODA del contexto de los proyecto de CE como campo de la CID en Paraguay

\section{FORTALEZAS}

Mejora de las condiciones macroeconómicas del país.

Realización de distintos planes con miras a potenciar la competitividad.

Producción de bienes con demanda en el exterior.

Posibilidad de establecer clústers con productos que poseen potencial.

Condiciones favorables para el desarrollo de inversiones.

Funcionamiento de Ventanilla Única de Exportación.

Avances en las certificaciones de calidad.

Mejor capacitación de los funcionarios en temas vinculados al CE.

Pertenencia del país a distintos esquemas de integración. 


\section{OPORTUNIDADES}

El CE es percibido como un área susceptible de apoyo por parte de los donantes.

Expertise de los donantes en materia de proyectos relacionados al CE.

Existen instituciones como la omc que impulsan mejores condiciones para los países menos avanzados en materia de CE.

Proliferación de tratados de libre comercio y búsqueda de apertura de mercados.

Situación del MERcosur obliga a un replanteo del esquema de integración.

\section{DEBILIDADES}

La institucionalidad del país en forma general es débil y la relacionada al CE no escapa a esto.

Distintas reformas clave fueron abandonadas.

La producción del país sigue centrada en pocos rubros y los mismos no poseen un elevado nivel de industrialización.

Los sucesivos gobiernos van variando de planes sin que exista una política claramente definida para la inserción económica del país.

Ratificación parlamentaria enlentece el proceso de cooperación.

Los procesos licitatorios y de contratación de personal en el sector público son muy lentos en el país.

Gestión de la cooperación aún es atomizada.

No existen bases de datos centralizadas de todos los proyectos realizados.

La evaluabilidad de los proyectos no es la óptima.

La competitividad del país es baja, 


\section{AMENAZAS}

Los fondos son cada vez más escasos.

Existe cierta condicionalidad para la concesión de fondos que no siempre puede ser afrontada por los países beneficiarios en este caso, Paraguay.

Entorno comercial mundial estancado.

Mercosur no cumple con sus objetivos trazados.

La exigencia en materia de innovación y calidad a nivel internacional va creciendo continuamente.

La competitividad de los países crece constantemente.

Fuente: elaboración propia

A partir de los factores identificados, pueden apreciarse desafíos en tres dimensiones: política, institucional e inherente a los propios proyectos. En materia política, durante el período de análisis se registraron avances modestos, entre los que se encuentra un mayor diálogo entre las partes y contacto más cercano con las instituciones beneficiarias y con los cooperantes (Alcaraz, 2016). No obstante, al no existir una política clara en la temática, la coordinación se articula conforme a la necesidad y la proactividad de los responsables. Esto, y la posibilidad de que las instituciones obtuviesen fondos de cooperaciones de forma directa, sin compromiso de recursos gubernamentales paraguayos, llevó a que no exista una obligación de informar sobre estas actividades, lo que pudo conducir a que exista un registro incompleto de los proyectos de cooperación.

En materia institucional, los desafíos son muy importantes. Esta dimensión requiere de particular atención debido a que sirve como base para la implementación de los proyectos y su fortalecimiento es señalado frecuentemente como una de las razones que motiva a los donantes a cooperar con Paraguay, como se ha observado en los proyectos reseñados previamente. Acciones como el fortalecimiento de las instituciones que gestionan la cooperación, el desarrollo de las capacidades en las personas involucradas, el desarrollo de instancias de diálogo con los cooperantes y brindarles mayor previsibilidad, son ejemplos de necesidades que se aprecian en la materia (sTP et al., 2012).

Los aspectos relacionados a los propios proyectos también requieren de atención. Es fundamental que los mismos estén diseñados de manera que puedan ser minimizados sus costos y que los resultados sean fácilmente medibles, ya que ambas cuestiones favorecen la efectividad de los mismos. 
Finalmente, es importante señalar que conforme a datos de la омC (2020), se aprecia una evolución positiva del Aof dedicada al comercio. En la Tabla 6 se observa la evolución del financiamiento externo, el cual pese a no coincidir estrictamente con el período de referencia, señala que la AOD dedicada al comercio ha aumentado en 59,7\% entre 2006 y 2014.

Tabla 6: Entrada de financiamiento externo

\begin{tabular}{lll}
\hline $\begin{array}{l}\text { Entrada de financiamiento externo } \\
\text { (USD mill. corr.) }\end{array}$ & $\mathbf{2 0 0 6 / 0 8}$ & $\mathbf{2 0 1 4 / 1 6}$ \\
\hline IED & 186,7 & 346,0 \\
Remesas & 346,5 & 572,4 \\
Otros flujos oficiales (OFO) & 33,4 & 258,1 \\
OFO relacionados al comercio & 20,9 & 192,9 \\
Ayuda Oficial al Desarrollo (AOD) & 150,5 & 142,0 \\
AOD dedicada al comercio & 35,0 & 59,7 \\
\hline
\end{tabular}

Aspectos cuantitativos del comercio exterior paraguayo

Lo enunciado anteriormente es una importarte referencia, pero es preciso conocer adicionalmente la evolución de los distintos indicadores relacionados al comportamiento del CE paraguayo con un breve análisis de los mismos. Si bien estos no constituyen una evidencia inequívoca de los resultados de la cooperación recibida por el Paraguay en la materia, permiten tener una idea de la evolución.

El primero de los indicadores a ser considerado es el de las exportaciones totales de bienes que se observa en el Gráfico 1 (вср, 2015). En él puede apreciarse que el volumen de exportaciones tuvo una tendencia creciente y aumentó en $241 \%$ durante la década 2003-2013, pese a haberse registrado en 2009 y 2012 una disminución de su cuantía. Esto se debió fundamentalmente a problemas registrados con la sequía, que mermó la cosecha de soja y gatilló la aparición de un brote de fiebre aftosa, lo que sumado a la crisis económica global de 2009, afectó a las exportaciones. 
Gráfico 1: Exportaciones del Paraguay (2003-2013)

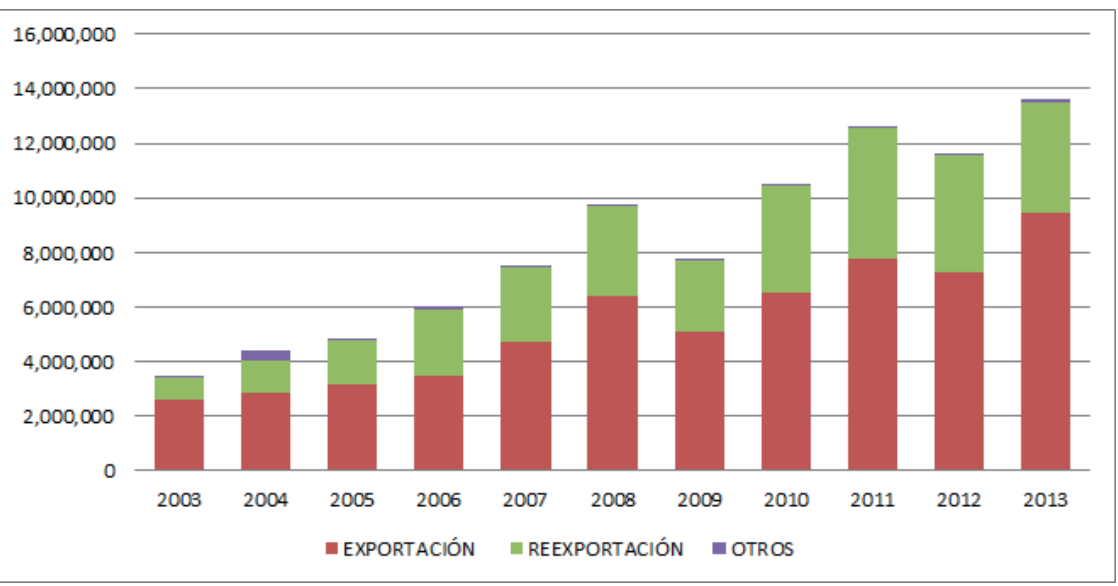

Fuente: Elaboración propia en base a datos del BCP (2015)

La alta dependencia de los productos agrícolas, los cuales a su vez se encuentran expuestos a cuestiones como el clima o las plagas y afecciones, pone de manifiesto la escasa sofisticación de las exportaciones y deja entrever que pese a los esfuerzos realizados, los productos ofrecidos por el Paraguay al mundo aún no evidencian un nivel de sofisticación que permita modificar la configuración histórica que tiene el país de ser exportador de materias primas.

En el Gráfico 2 se pueden apreciar las exportaciones del Paraguay organizadas en cuatro rubros, a saber: productos primarios, manufacturas de origen agropecuario, manufacturas de origen industrial, y combustibles y energía. El rubro "Productos primarios" es uno de los principales en materia de exportación y entre sus componentes puede encontrarse, como principales productos de exportación, la soja, el maíz, el trigo, el arroz, las fibras de algodón, las semillas de sésamo, el carbón vegetal, las semillas de nabo y el tabaco sin elaborar, entre otros. En promedio, "Productos primarios" ha significado el $31 \%$ de las exportaciones del país.

Sobre la alta incidencia de los recursos naturales en las exportaciones paraguayas, es preciso realizar un paréntesis para señalar que el período de análisis de este trabajo coincide con el boom de los commodities registrado en la región, el cual tuvo efectos heterogéneos entre los países. Si bien Grijalva \& Martínez (2014) sostienen que este fenómeno posibilitó una mejora de los indicadores económicos, autores como Sachs afirman que los países que poseen abundantes recursos naturales 
tienden a crecer menos (Kosacoff \& Campanario, 2007). Independientemente de este contrapunto - que merece un estudio acabado que escapa al objetivo de este material-, cabe resaltar que este boom fue un factor exógeno que impulsó las exportaciones paraguayas en el período analizado. Como indicador de esto puede citarse a Ocampos (2017), quien refiere que la dependencia de las exportaciones paraguayas es una de las más elevadas de América Latina, situándose en torno al 91,2\%.

Para dar continuidad al detalle de los rubros de exportación detallados en el Gráfico 2, cabe señalar que las "Manufacturas de origen primario" también son un rubro de mucha significancia para las exportaciones del país, representando para el período 2003-2013 un promedio del 26\% de las exportaciones. El rubro con menor preponderancia es el de las manufacturas de origen industrial, cuyo promedio de participación es de solamente el $6,27 \%$.

El último de los rubros a considerar es el de "Combustible y energía", aunque podría ser considerado solo como "Energía eléctrica", ya que es esta la línea que tiene prácticamente la exclusividad de su composición. Su aporte en materia de exportaciones es clave para el Paraguay, ya que oscila en un porcentaje cercano al 37\% en promedio. 
Comercio exterior como campo de la cooperación internacional al desarrollo en Paraguay. Los proyectos implementados en el período 2003-2013

Gráfico 2: Composición de las exportaciones paraguayas (2003-2013)

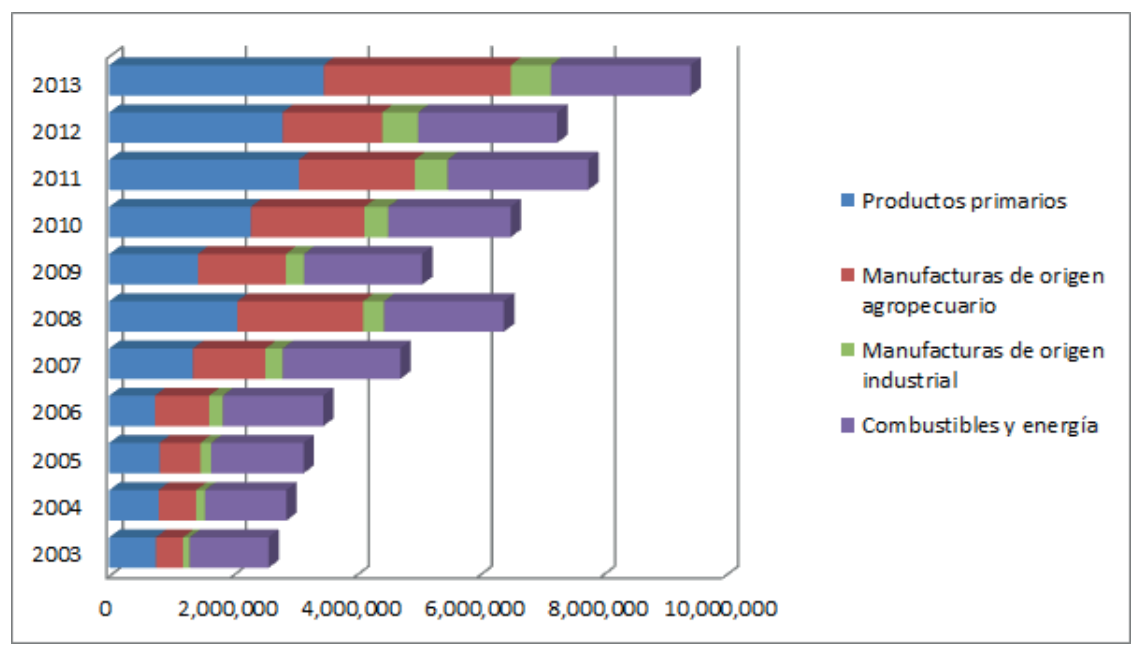

Fuente: Elaboración propia en base a datos del BCP (2015)

Otra de las variables a ser consideradas como parte del CE paraguayo son las importaciones de bienes y las mismas están clasificadas en "importaciones" y "otros". Las importaciones, al igual que las exportaciones, también mostraron una tendencia positiva, aunque no escaparon de los efectos adversos de las dificultades presentadas en los años 2009 y 2012.

En el Gráfico 3 se aprecia la evolución del saldo entre las exportaciones e importaciones totales. Si bien este indicador muestra solamente la diferencia entre ambas variables, es interesante de analizar. En el caso de países como Paraguay, las importaciones pueden reflejar la compra de insumos y maquinarias necesarios para la producción, por lo cual su crecimiento acompaña en muchos casos a las exportaciones. Por esto, puede relacionarse con que si bien las exportaciones registraron un aumento progresivo y esto condujo a que el saldo observado sea positivo, es evidente la fluctuación registrada en el saldo. 
Gráfico 3: Saldo de la Balanza Comercial

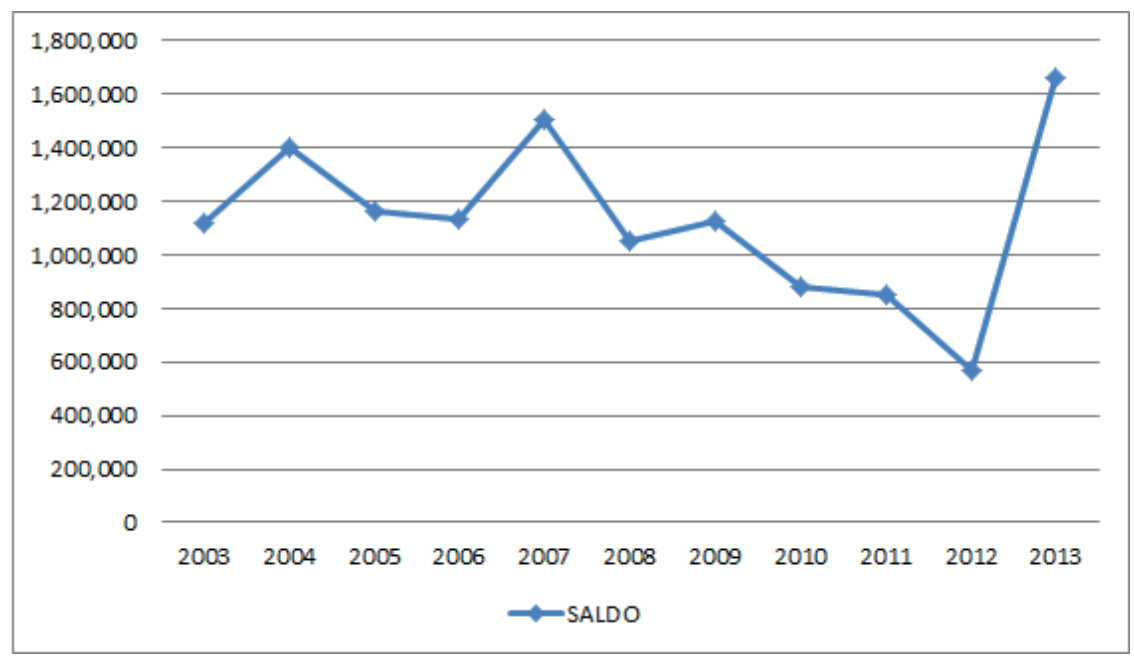

Fuente: Elaboración propia en base a datos del BCP (2015)

La cuenta corriente de la balanza de pagos merece un apartado especial en nuestro análisis. Es importante hacer notar que a partir de 2012 el Banco Central del Paraguay consideró la inclusión del $50 \%$ de la producción de las dos grandes binacionales que posee el país con sus vecinos: Itaipú (en copropiedad con Brasil) y Yacyretá (en copropiedad con Argentina).

Esta inclusión mejoró notoriamente el desempeño económico del país, el cual sin estos importes posee una posición comercial muy distinta, con un nivel de exportación mucho menor y centrado en productos agrícolas. Si bien a partir de esta modificación el país cuenta con un nuevo perfil, es preciso notar que la dependencia de la economía del sector agropecuario sigue siendo evidente y que la producción de energía a partir de hidroeléctricas ya alcanzó su tope, por lo que no aportaría más que lo que contribuye actualmente, a menos que experimente una variación en su cantidad o precio (Ozuna, 2015:12).

Antes de este cambio metodológico, la misma se mostró muy volátil a través de la década. Pese al notorio crecimiento experimentado por las exportaciones, especialmente de commodities, también creció la importación de bienes importados. A modo de reseñar, basta con mencionar que las exportaciones en 2003 totalizaban un monto próximo a los USD 3.450 millones, mientras que en 2013 esta cifra trepó a los usD 13.600. Por su parte, las importaciones pasaron de una cuantía cercana a USD 2.320 en 2003 a aproximadamente USD 12.000 en 2013. 
El componente servicios, en tanto, ha tenido un comportamiento deficitario para todos los años de esa década, con excepción de 2009. De la misma manera, el componente renta ha evidenciado un profundo déficit. Finalmente, las transferencias corrientes mostraron una tendencia favorable, debido fundamentalmente a las remesas de los paraguayos que se encuentran en el exterior.

Si bien la primera década del tercer milenio fue de mucha bonanza para los países americanos y sus commodi ties, esto se debió fundamentalmente a un aumento de los precios de estos productos: la elevada demanda mundial, impulsada fundamentalmente por China, y otros factores exógenos, como los problemas climáticos. Los países de la región se vieron beneficiados con esta coyuntura, pero esto no puede soslayar la necesidad de diversificar los productos de exportación, de manera de disminuir la dependencia.

En cuanto a la diversificación de productos, la омс (2020) sostiene que el número de productos exportados por Paraguay ha pasado de 342 en 2006 a 437 en 2017, sobre un máximo de $1.245^{7}$. Por su parte, el índice Herfindahl-Hirschman $(\mathbf{I H H})^{8}$ de exportacio-

7 Se considera el período 2006-2017 por ser los datos disponibles al momento de la elaboración del presente material.

8 Este índice sirve para evidenciar la concentración en un mercado. Un índice cercano a 1 evidencia una mayor concentración y cuando el mismo esté más próximo a 0 , una mayor diversificación. nes pasó de 0,249 a 0,139 en el mismo período. Ambos indicadores muestran un avance en la materia, aunque existe aún mucho trabajo por realizar al respecto.

La diversidad de mercados también registró avances, pasando de 101 mercados de exportación a 125. El IHH de concentración de mercados de exportación se redujo de 0,255 a 0,130 (2006-2017). Al igual que lo registrado, en cuanto a la concentración de productos ha habido progresos, pero considerando que el número máximo de mercados es 237, existe un notorio espacio de mejora (омc, 2020).

\section{Aspectos cualitativos del comercio exterior paraguayo}

A pesar de que, en términos cuantitativos, puede observarse cierto progreso en los indicadores generales, es preciso complementar el análisis con algunos aspectos cualitativos. Por esta razón, en estas líneas se reflexionará sobre la competitividad del Paraguay, para lo que se considerará el Índice de Competitividad Global (ICG).

Esta herramienta consta de 114 indicadores que evalúan los requerimientos básicos para efectuar negocios, los potenciadores de la eficienciay la innovación en los negocios (Schwab \& Sala-i-Martín, 2017). En la versión 2013, Paraguay se encontraba en el puesto 120 de 148,y a nivel regional su desempeño solo se encuentra por delante de Venezuela y Haití (Schwab \& Sala-i-Martín, 2013). 
Esta situación se debe a diversos motivos, entre los que se encuentran: la baja calidad de las instituciones, la escasa infraestructura, las carencias en materia educativa y de salud, la ineficiencia del mercado laboral, la carencia en materia de disponibilidad tecnológica, la pobre sofisticación de negocios y un nivel muy bajo de innovación.

Entre estos asuntos, uno corresponde a un aspecto puntual abordado en los proyectos considerados de ayuda al comercio: la baja calidad de las instituciones. Este tema fue recurrente en los proyectos emprendidos, sin embargo, los resultados fueron modestos. Este pilar considera aspectos como la seguridad, los derechos de propiedad y el desempeño del sector público, entre otros. Es de vital importancia porque inciden en el contexto en el que se realiza la actividad económica y tienen efectos en su productividad a través de incentivos y reducción de incertidumbre (Centro de Estudios sobre la Cuenca del Pacífico pujc, 2018).

Lo expuesto permite apreciar la importancia de este tema y su amplitud. Si bien los proyectos aquí considerados abarcaron solo una parte del mismo, los resultados globales de este indicador, y los ya señalados previamente en esta investigación, conducen a considerar que el mismo debería ser aún objeto de acciones para mejorar los resultados obtenidos.

\section{Conclusiones}

El concepto de BPG ha permitido justificar el abordaje de problemas transnacionales a través de la cooperación internacional y la misma se ha plasmado en diversos campos de acción. Uno de ellos es el CE. Para ello se han desarrollado instrumentos como: preferencias comerciales, cooperación económica, ayuda financiera, asistencia técnica y comercio justo, entre otras.

Estos instrumentos permitieron ejecutar distintos proyectos en Paraguay durante el período 2003-2013. Estos fueron ejecutados por diversos donantes, como: BID, JICA, UE, EE.UU., República de China-Taiwán, entre otros. Los proyectos tuvieron distintos enfoques, pero en su generalidad buscaron promover la diversificación de las exportaciones, en consideración de la reducida oferta exportadora del país y la alta dependencia del sector primario y sus mercados, y fortalecer la institucionalidad para así mejorar la competitividad.

Una evaluación de los resultados permite apreciar progresos en cuanto a la oferta exportable y los mercados de destino, aunque existe mucho espacio de mejora en ambos indicadores. Así también, si se analiza la competitividad del país, la posición de Paraguay se encuentra solo por detrás de Venezuela y Haití a nivel regional, 
situación que se ha mantenido en los últimos años.

Finalmente, es preciso señalar que esta temática tiene aún desafíos muy grandes en el país, por lo cual es preciso articular las acciones necesarias para que, desde el plano doméstico así como desde la ciD, se desarrollen proyectos que mejoren el desempeño del CE y la propia competitividad del Paraguay.

\section{Bibliografía}

Abente Brun, D. (2019). 1989 (Vol. 10). El Lector.

Alonso, J.A. (2015). Más allá de la ayuda. Redefiniendo el sistema de cooperación para el desarrollo. En Gobernanza global y desarrollo (pp. 161-206). Grupo Editorial Siglo Veintiuno. https://repositorio.cepal. org/bitstream/handle/11362/38855/1/ GobernanzaGlobalyDesarrollo.pdf

Álvarez Orellana, S.M. (2012). Una introducción a la cooperación internacional al desarrollo. REDUR, 285-309.

Banco Central del Paraguay (2015). Anexo estadístico - Informe Económico. https:// www.bcp.gov.py/anexo-estadisticodel-informe-economico-i365

Banco Interamericano de Desarrollo. (2009).Evaluación del Programa de País: Paraguay 2003-2008. http://www.oecd. org/countries/paraguay/47813793.pdf

Banco Interamericano de Desarrollo. (2006a). Documento conceptual de proyecto. http://idbdocs.iadb.org/wsdocs/ getdocument.aspx?docnum $=832602$

Banco Interamericano de Desarrollo. (2006b). Esquema de proyecto PRL1018: Programa de Apoyo a las Exportaciones Paraguayas. http://idbdocs. iadb.org/wsdocs/getdocument. aspx? docnum $=751988$

Cabral López, M.A. (2017). Paraguay: un análisis de su participación y desafíos futuros en el sistema multilateral de comercio (1995-2016). Revista Encrucijada Americana, 9(2), 28-44.

Cabral López, M.A. (2014). Cooperación bilateral con el Paraguay: una breve reseña de su desarrollo entre 1954 y 1989. Revista Población y Desarrollo,39,96-107. Calabuig Tormo, C.; Gómez-Torres, M.; Boni Aristizábal, A.; Cuesta Fernández, I.; Lozano Aguilar, J.F.; Monzó Balbuena, J.M., \& Torres Martínez, A.J. (2010). La Cooperación Internacional para el Desarrollo. Edición revisada. (Calabuig Tormo, Carola y Gómez-Torres María). Fustabloc. http://www.upv.es/ upl/U0566378.pdf

CARANA Corporation. (s.f.). Paraguay Productivo. Final report. United States Agency for International Development. https://www.usaid.gov/sites/default/files/documents/1862/final report paraguay productivo.pdf

Centro de Estudios sobre la Cuenca del Pacífico, Pontificia Universidad Javeriana de Cali. (2018). El Índice de 
Competitividad Global. 3(4). https:// www.javerianacali.edu.co/sites/ujc/ files/Publicaciones/boletin cecp vol 3 no 4.pdf

Chemonics International Inc. (2010). Paraguay Poverty Reduction Program Final Evaluation Report. http://www.paraguayvende.com.py/publicaciones/Final Evaluation.pdf

Comisión Económica para América Latina y el Caribe, \& Agencia de Cooperación Internacional del Japón (JICA) (2013). Estudio sobre el desarrollo inclusivo del Paraguay. Experiencias de una cooperación internacional.http://www.cepal.org/es/ publicaciones/1503-estudio-sobre-eldesarrollo-inclusivo-del-paraguayexperiencias-de-una

Comisión Europea (2008). El régimen especial de estímulo del desarrollo sostenible y la gobernanza (SPG+) 2009-2011 de la Comunidad Europea. http://europa.eu/rapid/ press-release MEMO-08-777 es.htm

D’Alisa, G. (2013). Bienes comunes: las estructuras que conectan. Ecología política, 45. https://www.ecologiapolitica.info/novaweb2/wp-content/ uploads/2015/12/045 DAlisa 2013. pdf

Delegación de la Comisión Europea en Paraguay (2009). Relaciones Unión Europea-Paraguay. http://eeas.europa. eu/delegations/paraguay/documents/ press corner/publication/final copy librocoop.pdf

Dirección Nacional de Aduanas (2010). Ventanilla Única del Importador (VUI). Aduana Paraguay. http://www.aduana. gov.py/125-6-ventanilla-unica-delimportador--vui-.html

Escribano Francés, G. (2012). Provisión de bienes públicos globales y economía política internacional. Anuario de la Facultad de Derecho de la Universidad Autónoma de Madrid,16(2012), 39-54.

Espínola González, Z. (2010). Historia Económica del Paraguay (1811-2010) (Vol.20). El Lector.

García Arias, J. (2004). Un nuevo marco de análisis para los bienes públicos: la Teoría de los Bienes Públicos Globales. Estudios de Economía Aplicada, 22(2), 187-212.

Grijalva, D. \& Martínez, M.C. (2014). El fin del súper ciclo de los Commodities y su impacto en América Latina. https://www. usfq.edu.ec/publicaciones/koyuntura/ Documents/koyuntura 2014-48.pdf

Kaul, I. \& Blondin, D. (2015). Los bienes públicos globales y las Naciones Unidas. En Gobernanza global y desarrollo. Grupo Editorial Siglo Veintiuno. https://repositorio.cepal.org/bitstream/ handle/11362/38855/1/GobernanzaGlobalyDesarrollo.pdf

Kaul, I., Grunberg, I., \& Stern, M. (Eds.). (1999). Global public goods. International cooperation in the 21st century. United Nations Development Programme.

Kosacoff, B. \& Campanario, S. (2007). La revalorización de las materias primas $y$ sus efectos en América Latina. Comisión Económica para América Latina y el Caribe. https://repositorio.cepal. org/bitstream/handle/11362/3561/1/ $\underline{\text { S2007306.pdf }}$ 
Masi, F. \& Rojas, G. (2019). La inserción internacional del Paraguay en democracia. El Lector.

Masi, F. (2006). Paraguay: los vaivenes de la politica comercial externa en una economía abierta. Centro de Análisis y Difusión de la Economía Paraguaya. http:// biblioteca.clacso.edu.ar/Paraguay/ cadep/20160722054744/11.pdf

Morrissey, O., te Velde, D. w., \& Hewitt, A. (2002). Defining international public goods: conceptual issues. En International Public Goods. Incentives, Measurement, and Financing (pp. 31-46). http:// documents.worldbank.org/curated/ en/138101468327354525/pdf/multi0page.pdf

Ocampo, J.A. (2017). Commodity-led Development in Latin America. En G. Carbonnier, H. Campodónico, \& S. T. Vázquez (Eds.), Alternative Pathways to Sustainable Development: Lessons from Latin America (pp. 51-76). Brill; JSTOR. www.jstor.org/stable/10.1163/j. ctt1w76w3t.11

Organización Mundial de Comercio. (2020). Paraguay - Información por Miembro. https://www.wto.org/ spanish/thewto s/countries s/ paraguay s.htm

Organización Mundial de Comercio. (s. f.). Arreglos comerciales Preferenciales. Recuperado 22 de enero de 2020 , de http://ptadb.wto.org/Country. aspx? code $=600$

Organización para la Cooperación y el Desarrollo Económicos (OCDE). (2018). Estudio multidimensional de Paraguay Volumen 1. Evaluación inicial.
Organización para la Cooperación y el Desarrollo Económicos (OCDE). https://www.oecd.org/development/ mdcr/countries/paraguay/ Paraguay Vol 1 Overview Sp.pdf

Ozuna, R. (2015). "Impacto generado en la economía paraguaya, por la inclusión de las transacciones de las entidades binacionales Itaipú y Yacyretá en las cuentas nacionales y en la balanza de pagos. Periodo 1994 al 2010”. Universidad Nacional de Asunción.

Prado Lallande, J.P. (2003). La cooperación internacional y el comercio internacional. En La OMC y la Ronda de Doha: ¿proteccionismo vs desarrollo? UNAM-SELA.

Prado Lallande, P.; Ochoa Bilbao, L. \& Rodríguez Añuez, M. (s.f.). Visiones, enfoques y tendencias de la cooperación internacional para el desarrollo. Hacia un marco conceptual y práctico latinoamericano y caribeño. Recuperado 3 de enero de 2020, de https://www.academia.edu/5634039/ Visiones enfoques y tendencias de la cooperaci\%C3\%B3n internacional para el desarrollo. Hacia un marco conceptual y pr\%C3\%A1ctico latinoamericano y caribe $\% \mathrm{C} 3 \% \mathrm{~B} 10$

Programa de Apoyo a la Internacionalización Económica del Paraguay (2013). Grupos Beneficiarios. http://www.aiep. gov.py/beneficiarios

Programa UMBRAL (s.f.). Poder Judicial. Recuperado 29 de diciembre de 2015, de http://www.pj.gov.py/ contenido/445-programa-umbral/595 
Ramis Olivos, A. (2013). El concepto de WEFGlobalCompetitivenessReport 2013-14.pdf

Schwab, K., \& Sala-i-Martín, J. (2013b). The Global Competitiveness Report 2017-2018. Foro Económico Mundial. http://www3.weforum.org/ docs/GCR2017-2018/05FullReport/ TheGlobalCompetitivenessReport2017\%E2\% 80\% 932018.pdf

Secretaría Técnica de Planificación de Desarrollo Económico y Social, Ministerio de Relaciones Exteriores, \& Ministerio de Hacienda. (2012). La cooperación internacional no reembolsable en el Paraguay a diciembre de 2011. http://www.economia. gov.py/v2/sistema/files/files/Informe Cooperacion Digital V2-20120426171213.pdf

Stiglitz,J. (2000). Los bienes públicos y los bienes privados suministrados por el
Estado. En La economía del sector público (3ra ed., pp. 149-181). Antoni Bosch Editor.

Tabares, S., Anzo, E. \& Estrada, L.M. (2014). La cooperación internacional en la internacionalización de pequeñas y medianas empresas de Medellín: un estudio de caso comparado. Estudios Gerenciales, 30, 314-324.

Tamames, R. \& Huerta, B. (2010). Integración económica en las Américas (II). ALALC, ALADI, CAN, G-3, MERCOSUR, ALACSA. En Estructura Económica Internacional (21 ${ }^{\mathrm{a}} \mathrm{ed}$.). Alianza Editorial. UNCTAD (2018). Comercio, cooperación multilateral y desarrollo sostenible. https://unctad.org/meetings/es/ SessionalDocuments/cid45 es.pdf

Uscanga, C. (2011). La cooperación triangular México-Japón. Revista Española de Desarrollo y Cooperación, 28, 83-93. 